\title{
As avaliações em larga escala na formação de professores de Matemática e supervisores de um município da região metropolitana de Porto Alegre
}

\author{
Large-scale assessments in Mathematics' teachers and supervisors' training of a \\ municipality of metropolitan region of Porto Alegre
}

\author{
Ednei Luís Becher \\ Instituto Federal de Educação, Ciência e Tecnologia do Rio Grande do Sul (IFRS) \\ Campus Osório, Osório, RS, Brasil \\ https://orcid.org/0000-0001-8770-2424, ednei.becher@osorio.ifrs.edu.br
}

\author{
Jutta Cornelia Reuwsaat Justo \\ Universidade Luterana do Brasil (ULBRA) \\ Programa de Pós-Graduação em Ensino de Ciências e Matemática, Canoas, RS, Brasil \\ https://orcid.org/0000-0001-5110-1571, juttareuw@gmail.com
}

\begin{tabular}{l}
\hline Informações do Artigo \\
\hline Como citar este artigo \\
BECHER, Ednei Luís; JUSTO, Jutta Cornelia \\
Reuwsaat. As avaliações em larga escala na \\
formação de professores de Matemática e \\
supervisores de um município da região \\
metropolitana de Porto Alegre. REMAT: \\
Revista Eletrônica da Matemática, Bento \\
Gonçalves, RS, v. 6, n. 1, p. 01-13, abr. 2020. \\
DOI: \\
https://doi.org/10.35819/remat2020v6i1id3668
\end{tabular}

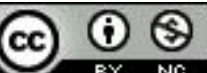

Histórico do Artigo

Submissão: 26 de setembro de 2019.

Aceite: 27 de dezembro de 2019.

\section{Palavras-chave}

Ensino de Matemática

Avaliação em Larga Escala

Formação de Professores

Prova Brasil

\section{Resumo}

Este trabalho apresenta resultados parciais de uma investigação que aconteceu com professores que ensinam Matemática no Ensino Fundamental e supervisores escolares em um município da região metropolitana de Porto Alegre, na qual se buscou identificar o que os participantes da pesquisa sabiam sobre a Prova Brasil de Matemática e onde adquiriram esses conhecimentos. Desenvolveu-se uma investigação qualitativa, a partir da qual os resultados encontrados sugerem que tanto os professores de Matemática quanto os supervisores escolares têm pouco conhecimento sobre os sistemas de avaliação em larga escala (Prova Brasil) implementados pelo Governo Federal e, da mesma forma, não sabem como utilizar ou integrar esses resultados ao seu planejamento. Além disso, os resultados indicam que os órgãos responsáveis pela avaliação poderiam incluir, entre as iniciativas de divulgação dos resultados, eventos nos quais os professores e supervisores tivessem a oportunidade de analisá-los de forma mais detalhada.

\section{Keywords}

Mathematics Teaching

Large-Scale Assessment

Teachers Training

Test Brasil

\begin{abstract}
This paper presents partial results of an investigation that happened with schools' supervisors and Mathematics' teachers of Elementary School, in a municipality of the metropolitan region of Porto Alegre, in which it was tried to identify what the participants of the research knew about the Test Brazil of Mathematics. A qualitative research was developed, from which the results suggest that both Mathematics' teachers and school supervisors have lack of knowledge about the large-scale evaluation systems implemented by the Brazilian Federal Government and, in the same way, they do not know how to use or integrate these results into their classroom or professional planning. The results also indicate that the responsible for national assessment should include initiatives to disseminate the results, promoting events in which teachers and supervisors have the opportunity to reflect and analyze the results in more detail.
\end{abstract}




\section{Introdução}

As avaliações em larga escala vêm ganhando relevância no planejamento educacional brasileiro (BAUER, 2012), onde também passaram a exercer grande influência sobre a forma como a sociedade percebe a qualidade da educação, principalmente em virtude da divulgação dos resultados das avaliações nacionais e de estudos comparativos internacionais pela imprensa (AMARO, 2013; BROOKE; SOARES, 2008) e pela repercussão social gerada.

Diante desse cenário, no qual o papel da escola e a percepção social do trabalho desenvolvido pelos professores está cada vez mais relacionado a parâmetros externos e à forma como a mídia divulga os resultados, trazemos um recorte de uma pesquisa qualitativa que investigou o que professores de Matemática e supervisores escolares de um município da região metropolitana de Porto Alegre conhecem sobre o uso dos resultados do Sistema de Avaliação da Educação Básica (Saeb), em particular, da Prova Brasil de Matemática.

Entende-se que investigar sobre os resultados da Prova Brasil de Matemática é relevante, pois as avaliações externas influenciam a forma como a sociedade percebe o trabalho docente, o que torna importante conhecer o que professores e supervisores sabem sobre elas e como utilizam os resultados dessa avaliação. Além disso, tem sido visto que a Prova Brasil de Matemática tem repercussões no currículo escolar que, em muitos casos, é ajustado às matrizes de referência em uma tentativa de melhorar os resultados dos estudantes nessa avaliação; no entanto, essa ação torna o currículo de Matemática empobrecido (CERDEIRA; ALMEIDA; COSTA, 2014).

Este artigo principia por pontuar reflexões recentes sobre os objetivos, estrutura e utilização das avaliações externas em larga escala e, na sequência, o texto converge para a caracterização e problematização do Sistema de Avaliação da Educação Básica (Saeb), com foco na Prova Brasil. Na sequência, é descrita a metodologia empregada no desenvolvimento da investigação, seguida pela apresentação e discussão dos resultados obtidos.

\section{Avaliação Educacional}

A partir da implementação das avaliações de larga escala no final da década de 1980 e início da década de 1990, se estabeleceu, em muitos setores da sociedade, uma correlação entre a aprendizagem dos alunos e os resultados dos testes usados nas avaliações (DALBEN; ALMEIDA, 2015). Uma consequência disso foi o papel central que a avaliação da aprendizagem passou a ter (GIMENES et al., 2013), figurando como elemento principal na análise e no financiamento dos sistemas educativos e de suas instituições e sendo adotada, conforme Sousa et al. (2012), para o monitoramento do desempenho escolar por meio de comparações entre o aprendizado esperado e o nível de proficiência indicado nos resultados obtidos pelos estudantes.

Apesar de não ser aceita por todos, a disseminação entre as diferentes esferas de governo (BAUER, 2012; BAUER; REIS, 2013; BONAMINO, 2013; BROOKE; CUNHA; FALEIROS, 2011) 
indica a consolidação das práticas de avaliação em larga escala no cenário nacional. Essa expansão está relacionada com as reformas educacionais que deram mais autonomia às escolas, mas que, por outro lado, induziram os gestores a assumirem uma posição cada vez mais regulatória, com foco na excelência, eficácia e eficiência motivadas pela competitividade e outros aspectos da racionalidade econômica (MARTINS, 2002).

Percebe-se que existe uma grande diferença nos objetivos e uso dos resultados entre a avaliação concebida para a sala de aula e a prática pedagógica e aquela concebida para os sistemas ou redes de ensino. A primeira busca oferecer subsídios para os professores avaliarem seus métodos de ensino e a aprendizagem do aluno, enquanto a segunda propõe avaliar se e como uma determinada rede de ensino está alcançando seus objetivos ao longo da trajetória escolar dos estudantes. Todavia, é importante percebermos que a forma de avaliação adotada será influenciada pelas expectativas que se tem em relação a ela, o que também implicará na escolha dos métodos a serem empregados (NOVAES; TAVARES; GIMENES, 2011).

A busca por aproximar essas duas formas de avaliação passa pela elaboração e implantação de currículos mínimos. Para Silva Junior (2012), além da complexidade necessária a instrumentos de avaliação destinados a avaliar conceitos ou saberes de alto nível, outra questão que torna complexa e complicada a tarefa de desenvolver uma avaliação em uma escala nacional no Brasil é o fato de que "[...] nós ainda não temos um sistema nacional de educação que, por sua vez, significaria a expressão de um projeto nacional de educação, que, por sua vez e finalmente, significaria a expressão de um projeto-nação" (SILVA JUNIOR, 2012, p. 63).

Os sistemas de avaliação também têm sido uma das formas pelas quais o Estado influencia as ações pedagógicas da escola, sendo um instrumento de política educacional que interfere no padrão de qualidade de redes e sistemas de ensino. Como afirma Vianna (2005, p. 17), a "[...] avaliação educacional não subsiste isoladamente, devendo estar associada a outros programas, destacando-se, inicialmente, o de capacitação docente [...]" e, ao mesmo tempo, existe a necessidade de que as avaliações busquem identificar e indicar soluções para problemas educacionais realmente importantes para as redes de ensino e para todos os envolvidos.

Para Esquinsani (2012), ainda que as avaliações externas sejam um instrumento de política educacional, esse tipo de avaliação não pode ser realizado unilateralmente pelo Estado sem que exista discussão sobre seus métodos, sua concepção e sobre as formas como os resultados serão interpretados pelos estudantes, pais e sociedade. Nesse sentido, Vianna (2014) destaca que é preciso mitigar problemas na divulgação dos resultados, os quais levam professores, gestores, pais e alunos a utilizarem os resultados de forma equivocada. Logo, desenvolver estratégias para que a avaliação educacional não se limite a fornecer informações para a cúpula administrativa dos sistemas ou redes de ensino deve ser uma preocupação constante dos gestores e pesquisadores (ALAVARSE; BRAVO; MACHADO, 2013). 
No Brasil, percebe-se que há interesse em divulgar resultados, apesar da demora que caracteriza a divulgação dos resultados de certas avaliações, como referido por Gimenes et al. (2013). Atualmente, no caso da Prova Brasil, os resultados são divulgados durante o segundo semestre do ano seguinte ao da aplicação da prova, o que dificulta o uso pedagógico dos mesmos pelos professores.

Para Vianna (2005), divulgações isoladas, sem que se promovam estudos analíticos e uma análise crítica dos resultados, são pouco eficazes para a melhoria do sistema educacional. Para o pesquisador, ao mesmo tempo que os resultados das avaliações não poderiam ser ignorados pelos professores, eles também não poderiam ser utilizados pelos gestores para justificar escolhas sem que tivessem sido discutidos anteriormente com professores responsáveis pela área avaliada em suas escolas.

A avaliação não é um valor em si e não deve ficar restrita a um simples rito de burocracia educacional; necessita integrar-se ao processo de transformação do ensino e da aprendizagem, contribuindo ativamente para o processo de transformação dos educandos (VIANNA, 2005, p. 16). Dessa forma, a relação entre o professor e o processo de avaliação deve ser considerada como um aspecto fundamental do planejamento e execução de avaliações em larga escala, como o Saeb.

Outro aspecto que precisa ser considerado em uma avaliação de um sistema educacional é que a avaliação não pode ficar restrita à sala de aula, pois ela não é o único espaço responsável pelos resultados (VIANNA, 2005). Logo, as avaliações precisam abranger todos os níveis da hierarquia da administração educacional, passando, inclusive, pelos níveis técnicos e administrativos.

\section{Sistema Brasileiro de Avaliação Educacional}

Apesar de iniciativas isoladas de avaliação de redes ou sistemas de ensino no Brasil remontarem à década de 1930, ou ainda ao final da década de 1970 e início da década de 1980 (VIANNA, 1995; GATTI, 1996; BONAMINO; FRANCO, 1999), é somente com o Saeb, na década de 1990, que as avaliações ganham atenção governamental e passam a ter o status de política pública.

A criação do Saeb e de outras formas de obtenção de dados sobre o sistema educacional brasileiro foi motivada pela atribuição constitucional e reiterada pela Lei das Diretrizes e Bases da Educação Nacional (LDB), segundo as quais é atribuição do Estado a coleta de informações estatísticas como forma de avaliar e aprimorar o sistema educacional.

Dessa forma, o Ministério da Educação, por meio do Instituto Nacional de Estudos e Pesquisas Educacionais Anísio Teixeira (Inep), tem desenvolvido iniciativas como o Saeb e o Censo Escolar, que têm se consolidado como importantes fontes de dados sobre a Educação Básica nacional. 
O desenvolvimento de um sistema nacional de avaliação teve o ano de 1988 como um marco importante, pois, nesse ano, o Ministério da Educação ampliou a abrangência da avaliação proposta pelo chamado "Projeto Nordeste" para todo o país (HORTA NETO, 2007), criando, assim, o Sistema de Avaliação das Escolas Públicas de $1^{\circ}$ Grau (Saep), que teve, ainda em 1988, a aplicação de um teste piloto nos estados do Paraná e do Rio Grande do Norte. Todavia, a avaliação em nível nacional somente ocorreu em 1990, com a primeira edição em 1991, que passou a ser chamada de Sistema de Avaliação da Educação Básica (Saeb).

O Saeb insere-se no contexto internacional de acompanhamento das redes de ensino por meio do uso de avaliações externas em larga escala. O Inep tem buscado, ao longo do processo de evolução do Saeb, desenvolver ferramentas, metodologias e técnicas que permitam atingir seus objetivos, dentre os quais cabe destacar o principal deles: fazer um diagnóstico do sistema educacional brasileiro e de fatores que possam interferir no desempenho dos estudantes, fornecendo um indicativo sobre a qualidade do ensino que é ofertado (BRASIL, 2016a). A Figura 1 representa graficamente o Sistema Brasileiro de Avaliação vigente na época da investigação.

Figura 1 - Estrutura do Sistema Brasileiro de Avaliação a partir de 2013 e vigente na época da investigação.

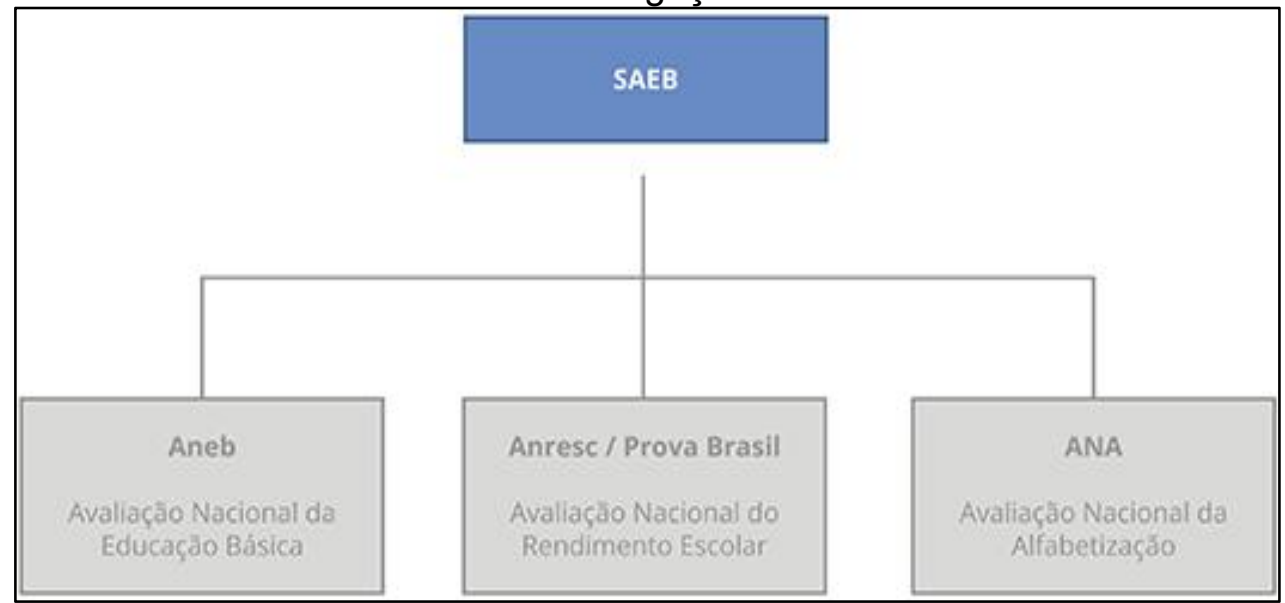

Fonte: Inep (2017, p. 7).

Particularmente, a Anresc (Prova Brasil), além de ser utilizada para avaliar programas e políticas governamentais, é um dos indicadores utilizados para o cálculo do Índice de Desenvolvimento da Educação Básica (ldeb), o que tem conferido muita importância a essa avaliação no cenário educacional e político.

Esse teste é aplicado de forma censitária a todos os estudantes da $4^{\mathrm{a}}$ série $/ 5^{\circ}$ ano e $8^{\mathrm{a}}$ série $/ 9^{\circ}$ ano do Ensino Fundamental, nas escolas públicas urbanas e rurais que tenham mais do que 20 alunos matriculados (BRASIL, 2016b), avaliando a proficiência dos estudantes em Língua Portuguesa, com foco em leitura, e Matemática, com foco na resolução de problemas.

Conforme a Portaria $n^{\circ}$ 482, de 07 de junho de 2013, a Prova Brasil tem por objetivos gerais (BRASIL, 2013, Art $3^{\circ}$ ):

I - avaliar a qualidade do ensino ministrado nas escolas, de forma que cada unidade escolar receba o resultado global; 
II - ser uma avaliação censitária, de larga escala, externa aos sistemas de ensino público, de periodicidade bianual;

III - contribuir para o desenvolvimento, em todos os níveis educativos, de uma cultura avaliativa que estimule a melhoria dos padrões de qualidade e equidade da educação brasileira e adequados controles sociais de seus resultados;

IV - concorrer para a melhoria da qualidade de ensino, redução das desigualdades e a democratização da gestão do ensino público nos estabelecimentos oficiais, em consonância com as metas e políticas estabelecidas pelas diretrizes da educação nacional; e

V - oportunizar informações sistemáticas sobre as unidades escolares.

O Saeb, desde sua primeira edição, em 1990 (BRASIL, 2016a; OCDE, 2016, 2017), esteve alinhado às concepções internacionais, incluindo os conteúdos de Matemática entre aqueles avaliados, tendo como foco a resolução de problemas. Segundo as concepções vigentes, as capacidades de leitura, interpretação e resolução de problemas utilizando conhecimentos matemáticos são as bases fundamentais para a aprendizagem de outros conteúdos matemáticos e disciplinas, assim como para a futura inserção dos estudantes no mundo do trabalho.

Além das provas, o Saeb possui questionários contextuais respondidos pelos alunos, professores e diretores das escolas que subsidiam as análises (BRASIL, 2016a, 2016b), sendo as habilidades e conteúdos avaliados organizados em matrizes de referência, as quais são recortes daquilo que tradicionalmente é ensinado nas escolas e consta em suas matrizes curriculares, as quais possuem os Parâmetros Curriculares Nacionais como base.

\section{Metodologia}

Os participantes da pesquisa foram professores que ensinam Matemática e supervisores ${ }^{1}$ da rede municipal de ensino de um município da região metropolitana de Porto Alegre, sendo a participação voluntária e desencadeada por meio de um convite para participarem de encontros de formação continuada sobre sistemas de avaliação e sobre a Prova Brasil de Matemática. Tal convite foi enviado pelo pesquisador por intermédio da Secretaria Municipal de Educação do município onde a investigação aconteceu.

Cabe destacar que a participação foi apoiada pela Secretaria Municipal de Educação, que não exigiu o comparecimento dos profissionais, mas viabilizou o local e a autorização para que os supervisores e os professores pudessem participar dos encontros.

No âmbito deste trabalho, se consideram como professores que ensinam Matemática aqueles que lecionam no $5^{\circ}$ ano do Ensino Fundamental e são licenciados em Pedagogia e os professores com licenciatura em Matemática que atuam nos anos finais do Ensino Fundamental.

A pesquisa foi desenvolvida em três etapas:

- Encontros de formação/investigação com os supervisores;

\footnotetext{
${ }^{1}$ Em determinadas regiões/cidades conhecido como supervisor e em outras como coordenador pedagógico.
} 
- Encontros de formação/investigação com professores de um projeto de formação continuada em Matemática existente no município;

- Encontros com professores de Matemática nas escolas da rede municipal.

Neste artigo serão analisados resultados parciais provenientes das duas primeiras etapas desenvolvidas, das quais participaram 21 professores e 18 supervisores.

A investigação desenvolvida adotou uma abordagem qualitativa, pois concordamos com Alves-Mazzotti e Gewandsznajder (1998, p. 131), para quem "[...] a principal característica das pesquisas qualitativas é o fato de que estas seguem a tradição 'compreensiva ou interpretativa', em que se pretende compreender de que forma as pessoas em um contexto particular pensam e agem".

Assumimos, ainda, que as etapas de uma pesquisa são desenvolvidas e integradas em um processo de análise que deve adaptar-se à investigação. Paviani (2006) destaca que não existem métodos prontos que possam ser usados sem adaptações, pois o método de pesquisa não pode ser aplicado como uma receita pronta e acabada, precisando sofrer adequações para cada caso investigado.

A análise do material obtido durante a investigação mostrou-se complexa devido à diversidade de registros que compreenderam entrevistas semiestruturadas, questionários e 0 material produzido pelos participantes. Assim, para análise dos dados, se assume que o processo de registro, organização e análise do material obtido ou produzido ao longo da investigação já se constitui em uma forma de "[...] aumentar a própria compreensão desses mesmos materiais e lhe permitir apresentar aos outros aquilo que encontrou" (BOGDAN; BIKLEN, 1994, p. 205).

Utilizou-se estatística descritiva para a apresentação de alguns resultados, a fim de que se tornassem mais elucidativos; no entanto, isso não descaracteriza a abordagem qualitativa da análise. Para a análise do material, se desenvolveu uma abordagem inspirada na Análise Textual Discursiva (MORAES, 2003), na qual se buscou identificar categorias de análise a partir de situações e manifestações que poderiam contribuir para a compreensão e contextualização.

\section{Resultados e Discussão}

De acordo com os questionários respondidos voluntariamente por parte dos participantes, eles não haviam estudado sobre avaliações em larga escala e/ou sobre os sistemas estatais (nacionais ou estaduais) de avaliação educacional durante seus cursos de graduação. Conforme a síntese apresentada na Figura 2, a maioria dos respondentes afirmou que não se lembrava de ter estudado sobre essas temáticas nas suas graduações. A situação evidenciada pela questão indica que o conhecimento dos professores de Matemática e supervisores participantes sobre as avaliações externas em larga escala tem origem, segundo suas respostas, em outras fontes diversas do curso de graduação. 
Figura 2 - Respostas à pergunta "Durante a sua graduação, você lembra de ter estuda sobre os sistemas de avaliação (Saeb, SAERS, ...) e a forma como são realizados?" $(N=26)$.

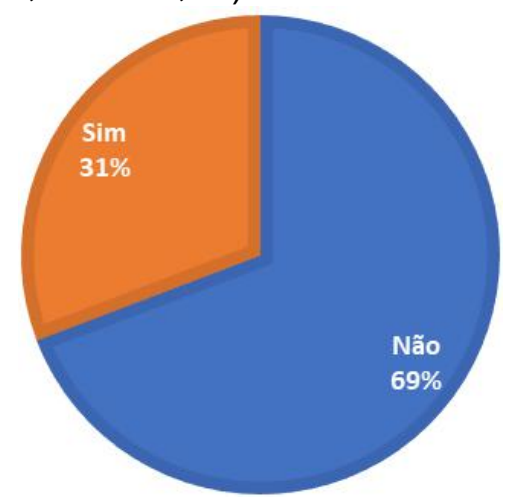

Fonte: Dados da pesquisa (2019).

Os supervisores e os professores também foram questionados em relação à possibilidade de utilização dos resultados das avaliações pelos gestores ou por professores para melhorar a aprendizagem dos estudantes nas escolas e, nesse sentido, os resultados apresentados na Figura 3 sugerem que, para os participantes, os resultados das avaliações externas em larga escala podem fornecer informações que permitam aos gestores e aos professores o aprimoramento das suas práticas e melhoria da aprendizagem. Porém, como será relatado na sequência, os professores sequer sabiam para que as avaliações serviam.

Figura 3 - Respostas à pergunta "Você acredita que os sistemas de avaliação implementados pelo Inep contribuem para a melhori da escola?" $(N=26)$.

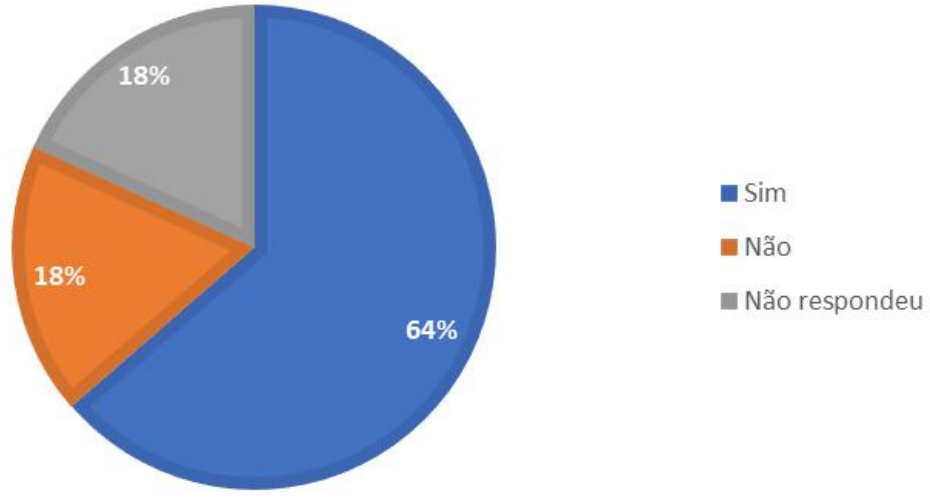

Fonte: Dados da pesquisa (2019).

Assim, embora seja possível que conteúdos relacionados à temática tenham sido tratados durante as graduações, os professores e supervisores participantes não lembraram, em sua maioria, de terem estudado sobre esses assuntos, o que nos leva a conjecturar que tal temática, caso tenha sido estudada, foi apenas marginalmente, contribuindo para aumentar as dificuldades na compreensão dos resultados das avaliações pelos professores (GIMENES et al., 2013) e ampliando as dificuldades técnicas para que isso aconteça (FREITAS, 2004). Contudo, a maioria dos participantes também considera que existe a possibilidade de uso dos resultados para a melhoria das práticas escolares, embora, de forma contraditória, não saibam precisar como seriam esses usos. 
Esses dois questionamentos iniciais, referentes à formação inicial e à visão dos participantes sobre o potencial de uso dos resultados, nos levaram a buscar, nas manifestações dos participantes, durante os encontros, excertos que pudessem ampliar a compreensão desses dois aspectos. O excerto a seguir, retirado de uma entrevista realizada com um supervisor, evidencia o pouco conhecimento sobre o tema, o que certamente é preocupante, tendo em vista que cabe ao supervisor articular, promover e auxiliar os professores na compreensão e interpretação dos resultados das avaliações. O trecho em destaque também sugere que algumas informações relativas ao uso dos resultados das avaliações são equivocadas.

Supervisor 2: - E daí o pessoal falava muito assim... isso aí é pra medir, é pra mandar dinheiro. Quem estiver melhor vai ganhar mais e quem estiver pouco vai ganhar menos e tem a influência da questão financeira, né.

A fala do Supervisor 2 não corresponde ao expresso nos documentos oficiais, porque, dentre as políticas ou programas implantados que consideram os resultados do Ideb/Prova Brasil (BRASIL, 2007, 2017a, 2017b), por exemplo, no Plano de Ações Articuladas (PAR), as escolas com desempenhos mais baixos é que deveriam receber maior volume de recursos e teriam preferência nos programas de apoio e capacitação, e não o contrário, como relatado pelo participante.

Nos três excertos a seguir, extraídos de transcrições de encontros de formação realizados com professores de Matemática, também é evidenciada a carência de conhecimento/formação relacionados aos objetivos e resultados das avaliações realizadas. Assim, considerando que os participantes tiveram uma formação inicial deficitária sobre o tema, nos parece que o órgão responsável pela realização da avaliação precisa aprimorar seus mecanismos e formas de comunicação com os professores nas escolas.

O Professor 5, que participou dos encontros de formação, destaca, no primeiro excerto a seguir, que reconhece a Prova Brasil e o Saeb como políticas públicas, mas enfatiza que não conhece o seu objetivo, e esse não conhecimento tem reflexo na participação efetiva dos alunos na resolução dos testes porque, uma vez que o professor não sabe para que serve a Prova Brasil, ele não sabe explicar o porquê da avaliação. Além disso, outro aspecto presente na fala do professor é a questão da contrapartida oferecida às escolas.

Professor 5: - Tá, mas vamos supor... é uma política pública de implantação a nível nacional e qual é o objetivo final, então dizer o que pro aluno... [...] Mas a contrapartida? Eu não consegui entender. O que vem em contrapartida. Uma escola vai muito bem e outra vai muito mal, o que uma tem de diferente?

O Professor 6 explicita as mesmas dúvidas ao afirmar que "- O que eu realmente vejo de ruim é o fato da gente não saber", ao se referir às finalidades da Prova Brasil. O professor reitera as afirmações do Professor 5 ao declarar que ele não sabe se a avaliação é boa ou ruim porque ele não conhece os resultados. Nesse ponto, cabe a ressalva de que o professor não está se referindo ao resultado da pontuação da escala de proficiência obtida pela escola e que consta dos 
relatórios de desempenho, mas aos resultados financeiros ou de apoio pedagógico que o resultado das avaliações possa produzir.

Professor 6: - O que eu realmente vejo de ruim é o fato da gente não saber. A gente não ter estas informações, a gente ficar no ministério do ar, entende. Porque assim ó... eu não sei se é bom, ou não é bom. Eu não tenho esse conhecimento pra avaliar. Eu não tenho o conhecimento pra dizer... lá na sua origem se isso não tinha uma grande função de fazer com que fosse... trouxesse benefícios pra escola, entende. Então acho que isso é ruim. A gente sempre fica nesse não conhecimento. E aí só filosofam.

O professor 6 também destacou que, durante a sua passagem pela Secretaria Municipal de Educação e nesses últimos anos, nos quais ele está trabalhando em uma escola, não lembra de terem sido discutidos os resultados da Prova Brasil. Logo, como o conhecimento dos resultados da Prova Brasil se restringe a pontuações em escalas de proficiência ou a índices, na concepção do Professor 6, quem inevitavelmente acaba sendo responsabilizado pelos resultados é o professor da turma que participou da avaliação.

Professor 6: - Mas isso não é discutido, né. Tipo assim... eu voltei pra escola em 2013, e estava na secretaria. Fiquei 12 anos fora de sala de aula, mas na parte pedagógica. E... desses anos que eu estou, de 2013 até agora nós nunca paramos pra discutir isso dentro da escola e eu tenho certeza que esta discussão não aconteceu antes também. Então quer dizer... quem carrega o peso de uma avaliação é o professor que a turma é submetida.

Dentro do contexto apresentado, a partir dos excertos e das respostas ao questionário, parece-nos plausível inferir que os participantes apresentam lacunas em sua formação inicial e continuada, as quais não oportunizaram aprender sobre esse tipo de avaliação. Isso se manifesta por meio do desconhecimento mesmo de aspectos básicos, como objetivos, resultados e possibilidades de utilização dos resultados.

\section{Considerações Finais}

Os resultados apresentados indicam que os órgãos responsáveis pela Prova Brasil devem promover iniciativas de divulgação dos resultados, oportunizando aos professores uma reflexão de forma mais minuciosa, superando, assim, a tradicional divulgação de resultados em escalas, que parece não ser bem compreendida pelos professores e supervisores.

Essa situação evidencia o distanciamento existente entre os professores nas escolas e as políticas de avaliação implementadas (GIMENES et al., 2013) mediante uma gestão educacional que, estimulada por organismos internacionais (BORGES, 2003), se voltou desde a década de 1990 para uma abordagem na qual o Estado exerce o papel de garantir a qualidade da educação através do controle por meio de sistemas externos de avaliação (DALBEN; ALMEIDA, 2015), em todos os níveis e esferas da educação brasileira (BAUER, 2012; BAUER; REIS, 2013; BONAMINO, 2013; BROOKE; CUNHA; FALEIROS, 2011).

Cabe destacar ainda que a ausência do assunto nas disciplinas dos cursos de graduação, responsáveis pela formação inicial dos professores de Matemática e dos supervisores, também é 
um fator que concorre para as dificuldades na assimilação e compreensão dos resultados, conforme já indicado por Freitas (2004).

Os resultados também sugerem que a capacidade limitada dos participantes em compreenderem os resultados das avaliações externas limita o seu uso na melhoria da aprendizagem de Matemática, pois não oportuniza reflexões no âmbito da escola sobre as práticas e o currículo adotado e parece indicar a adoção de medidas paliativas de eficácia duvidosa: adequação dos currículos escolares ao conteúdo dos exames e responsabilização do professor da série em que a prova é aplicada pela revisão de todos os conteúdos.

Portanto, a partir dos resultados apresentados, conclui-se que duas iniciativas que podem contribuir para o melhor aproveitamento dos resultados da Prova Brasil seriam: oportunizar, por parte dos órgãos responsáveis pelas avaliações, aos professores e supervisores, formação e materiais que pudessem suprir as lacunas deixadas na formação inicial; e inserção, nas grades curriculares dos cursos de graduação, de conteúdos relacionados ao Saeb e a avaliações em larga escala.

\section{Referências}

ALAVARSE, O. M.; BRAVO, M. H.; MACHADO, C. Avaliações externas e qualidade na Educação Básica: articulações e tendências. Estudos em Avaliação Educacional, São Paulo, v. 24, n. 54, p. 12-31, jan./abr. 2013.

ALVES-MAZZOTTI, A. J.; GEWANDSZNAJDER, F. O método nas ciências naturais e sociais: pesquisa quantitativa e qualitativa. São Paulo: Pioneira Thomson Learning, 1998.

AMARO, I. Avaliação externa da escola: repercussões, tensões e possibilidades. Estudos em Avaliação Educacional, São Paulo, v. 24, n. 54, p. 32-55, jan./abr. 2013.

BAUER A. Estudos sobre sistemas de avaliação educacional no Brasil: um retrato em preto e branco. Revista @mbienteeducação, São Paulo, v. 5, n. 1, p. 7-31, jan./jun. 2012.

BAUER, A.; REIS, A. T. Balanço da produção teórica sobre avaliação de sistemas educacionais no Brasil: 1988 a 2011. In: REUNIÃO NACIONAL DA ANPED, 36., 2013, Goiânia. Anais... Disponível em: http://www.36reuniao.anped.org.br/pdfs trabalhos aprovados/gt05 trabalhos pdfs/gt05 3375 tex to.pdf. Acesso em: 26 mar. 2020.

BOGDAN, R.; BIKLEN, S. Investigação qualitativa em Educação: uma introdução à teoria e aos métodos. Coleção Ciências da Educação. Porto/Portugal: Porto Editora, 1994.

BONAMINO, A. C. de. Avaliação educacional no Brasil 25 anos depois: onde estamos? In: BAUER, Adriana; GATTI, Bernardete A. (Orgs.). Ciclo de debates: vinte e cinco anos de avaliação de sistemas educacionais no Brasil: implicações nas redes de ensino, no currículo e na formação de professores. v. 2. Florianópolis: Insular, 2013.

BONAMINO, A.; FRANCO, C. Avaliação e política educacional: o processo de institucionalização do Saeb. Cadernos de Pesquisa, São Paulo, n. 108, p. 101-132, nov. 1999. 
BORGES, André. Governança e Política Educacional: a agenda recente do Banco Mundial. Revista Brasileira de Ciências Sociais, São Paulo, v. 18, n. 52, p. 125-138, jun. 2003.

BRASIL. Ministério da Educação. Fundo Nacional de Desenvolvimento da Educação. Plano de Ações Articuladas. s. d. Disponível em: http://www.fnde.gov.br/programas/par/par-apresentacao. Acesso em: fev. 2017.

BRASIL. Ministério da Educação. Instituto Nacional de Estudos e Pesquisas Educacionais Anísio Teixeira. Nota Técnica: Índice de Desenvolvimento da Educação Básica - Ideb. s. d. Disponível em: http://download.inep.gov.br/educacao basica/portal ideb/o que e o ideb/Nota Tecnica n1 con cepcaolDEB.pdf. Acesso em: fev. 2017.

BRASIL. Ministério da Educação. Instituto Nacional de Estudos e Pesquisas Educacionais Anísio Teixeira. Histórico: Saeb. s. d. Disponível em: http://portal.inep.gov.br/web/guest/educacaobasica/saeb/historico. Acesso em: 18 jan. 2016.

BRASIL. Ministério da Educação. Instituto Nacional de Estudos e Pesquisas Educacionais Anísio Teixeira. Semelhanças e Diferenças. s. d. Disponível em: http://portal.inep.gov.br/web/saeb/semelhancas-e-diferencas. Acesso em: 18 jan. 2016.

BRASIL. Ministério da Educação. Portaria 482 de 7 de junho de 2013. Dispõe sobre o Sistema de Avaliação da Educação Básica SAEB. Brasília: MEC, p. 17-18, 2013.

BRASIL. Casa Civil. Decreto 6094 de 24 de abril de 2007. Dispõe sobre a implementação do Plano de Metas Compromisso Todos pela Educação, pela União Federal, em regime de colaboração com Municípios, Distrito Federal e Estados, e a participação das famílias e da comunidade, mediante programas e ações de assistência técnica e financeira, visando a mobilização social pela melhoria da qualidade da educação básica. Brasília, 2007. Disponível em: www.planalto.gov.br/ccivil 03/ ato2007-2010/2007/decreto/d6094.htm. Acesso em: fev. 2017.

BROOKE, N. P.; CUNHA, M. A.; FALEIROS, M. A avaliação externa como instrumento da gestão educacional nos estados: relatório final. Belo Horizonte: Game/UFMG; Fundação Victor Civita, 2011. Disponível em: http://www.fvc.org.br/pdf/relatorio-avaliacoes-externas.pdf. Acesso em: 17 dez. 2015.

BROOKE, N.; SOARES, J. F. (Orgs.). Pesquisa em eficácia escolar: origem e trajetórias. Belo Horizonte: UFMG, 2008.

CERDEIRA, Diana Gomes da Silva; ALMEIDA, Andrea Baptista de; COSTA, Marcio da. Indicadores e Avaliação Educacional: percepções e reações a políticas de responsabilização. Estudos em Avaliação Educacional, São Paulo, v. 25, n. 57, p. 198-225, jan./abr. 2014.

DALBEN, Adilson; ALMEIDA, Luana Costa. Para uma avaliação de larga escala multidimensional. Estudos em Avaliação Educacional, São Paulo, v. 26, n. 61, p. 12-28, jan./abr. 2015.

ESQUINSANI, R. S. S. Entre o caráter regulatório e o potencial emancipatório do sistema de avaliação da Educação Básica. In: WERLE, Flávia Obino Corrêa. Avaliação em larga escala: questões polêmicas. Brasília: Liber libro, p. 209-228, 2012.

FREITAS, Dirce Nei Teixeira de. Avaliação da educação básica e ação normativa federal. Cadernos de Pesquisa, São Paulo, v. 34, n. 123, p. 663-689, 2004.

GATTI, B. A. Desenvolvimento de projeto de avaliação do sistema educacional no Estado de São Paulo. Estudos em Avaliação Educacional, São Paulo, n. 13, p. 19-26, 1996. 
GIMENES, N.; SILVA, V. G.; PRÍNCIPE, Lisandra M.; LOUZANO, Paula; MORICONI, Gabriela M. Além da Prova Brasil: Investimento em sistemas próprios de Avaliação Externa. Estudos em Avaliação Educacional, São Paulo, v. 24, n. 55, p. 12-32, abr./ago. 2013.

HORTA NETO, J. L. Um olhar retrospectivo sobre a avaliação externa no Brasil: das primeiras medições em educação até o SAEB de 2005. Revista Iberoamericana de Educación, Madrid, v. 42, n. 5., p. 1-14, 2007.

INEP. Instituto Nacional de Estudos e Pesquisas Educacionais Anísio

Teixeira. Sistema de Avaliação da educação Básica - Edição 2017. Projeto básico, v. 6. Disponível em:

http://download.inep.gov.br/educacao basica/saeb/2017/documentos/projeto basico SAEB 2017 V6.pdf. Acesso em: 26 mar. 2020.

MARTINS, Ângela Maria. Autonomia e descentralização: a (ex)tensão do tema na agenda das políticas educacionais recentes. Revista Portuguesa de Educação, Braga, v. 15, n. 1, p. 269-296, 2002.

MORAES, R. Uma tempestade de luz: a compreensão possibilitada pela análise textual discursiva. Ciência \& Educação, Bauru/SP, v. 9, n. 2, p. 191-211, 2003.

NOVAES, G. T. F.; TAVARES, M. R.; GIMENES, N. A. Modelos em avaliação: testes em larga escala. Revista Escola Pública, São Paulo, v. especial, p. 60-75, 2011.

OCDE. Organização para a Cooperação e Desenvolvimento Econômico. About PISA. Disponível em: http://www.oecd.org/pisa/aboutpisal. Acesso em: dez. 2017.

OCDE. Organização para a Cooperação e Desenvolvimento Econômico. Brasil no PISA 2015: análise e reflexões sobre o desempenho dos estudantes brasileiros. São Paulo: Fundação Santillana, 2016.

PAVIANI, J. Conhecimento científico e ensino: ensaios de epistemologia prática. Caxias do Sul: Educs, 2006.

SILVA JUNIOR, C. A. Avaliação de larga escala e organização do trabalho na escola. In: WERLE, Flávia Obino Corrêa. Avaliação em larga escala: questões polêmicas. Brasília: Liber Livro, 2012.

SOUSA, Clarilza Prado de; OLIVEIRA, Tarciso J. de; ROCHA Maria C.; DE SÁ, Ivo Ribeiro; SANTOS, Solange M. dos; ANDRADE SILVA, Simone de O.; SUGAHARA, Leila Y.; ALVES, Karina; STANICH, Biasoli; TAVARES, Antonio V. Dificuldades recorrentes dos alunos do $5^{\circ}$ ano do Ensino Fundamental em Matemática. Estudos em Avaliação Educacional, São Paulo, v. 23, n. 53, p. 198-221, set./dez., 2012.

VIANNA, H. M. Avaliação Educacional: uma perspectiva histórica. Estudos em Avaliação Educacional, São Paulo, n.12, p. 7-24, 1995.

VIANNA, H. M. Fundamentos de um Programa de Avaliação Educacional. Brasília: Liber Livro, 2005.

VIANNA, H. M. As contribuições de Heraldo Vianna para a Avaliação Educacional. Estudos em Avaliação Educacional, São Paulo, v. 25, n. 60, n. especial, dez. 2014. 